b boys and girls may have had different exposure to the events

c young children cannot have PTSD

d psychological reactions to traumatic events may vary according to developmental stage

e adolescents with PTSD will grow out of it.

3. The psychological well-being and social adjustment of young refugees:

a are mainly the responsibility of the NHS

$\mathrm{b}$ cannot be considered in relation to the Children Act 1989 (England and Wales)

c are not considered in recent social exclusion initiatives

$\mathrm{d}$ are helped by all government policies and laws

e probably improve spontaneously over time.

4. Young refugees:

a in view of the obstacles to referral, have greater social impairment when seen at Tier 3 clinics than non-refugees

b cannot access Tier 3 CAMHS

c are known to have higher rates of drop-out from Tier 3 services than immigrant or British comparison groups

d will not be referred by GPs and paediatricians e who attend Tier 3 clinics probably cannot be helped if interpreters are needed.

5. Regarding service provision and psychiatric treatments for young refugees:

a the voluntary sector does not contribute

b the evidence base may influence the choice of effective treatments

c attending for treatment is always initially associated with reduction of anxiety and distress

$\mathrm{d}$ individual psychological treatments are always the treatments of choice

e recounting past traumatic events is a requirement for treatment.

MCQ answers

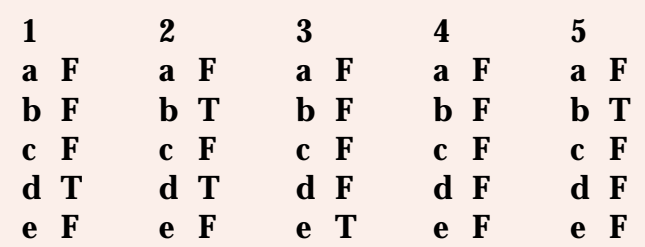

\title{
Commentary
}

\section{Gordana Milavic}

This commentary has been written after the World Trade Centre disaster in the USA and during an almost palpable re-examination of many of our values, particularly those related to the question of asylum-seekers, refugees and immigrants. In a new world order, where words such as war and civilian strife become imponderable, where it is near impossible at first glance to make out friend from enemy, how will societies be certain who is and who is not a refugee, and find the ability at the same time to respond to their increasing numbers? As new refugee camps around the world are set up and are swollen by thousands, as ships carrying asylum-seekers are denied docking, a political and social debate has been rekindled. What effect are these new policies, bills and guidelines likely to

Gordana Milavic is a consultant child and adolescent psychiatrist and the Clinical Director of the Child and Adolescent Mental Health Services of Oxleas NHS Trust in south-east London (Highpoint House, Memorial Hospital, Shooters Hill, London SE18 3RZ, UK). She has clinical and field experience in working with refugee children and young people, being particularly interested in the study of psychological trauma. 
have on public health issues related to the asylumseeking and refugee population?

Philosophers have already been concerned with the subject. Derrida (2001), writing several years ago, examined the original concept of hospitality in an essay on the subject of cosmopolitan rights for asylum-seekers, refugees and immigrants. He talked of 'open cities' (villes franches) and 'refuge cities'(villes refuges), where migrants might seek sanctuary from persecution and exile, and then contrasted this seemingly unconditional hospitality with the conditional and discriminatory laws that govern asylum applications. The tension between the two extremes is illustrated on one side by the increasing number of families, children and young people successfully resettling in other countries, and on the other by restricted entry, closed borders and refugee catastrophes, with subsequent impact on voluntary agencies, non-governmental organisations (NGOs) and other forms of humanitarian organisation. But in each case it is now even more important to understand what are the implications for mental health across local and national public health services and also across worldwide health service networks. Hodes (2002, this issue) has researched and written before on this subject, and in an area where work is often speculative, continues to base his work on sound methodology. He optimistically sets out with the premise that many refugees do not have 'significant psychiatric morbidity', although I would refer readers to other work by him (Hodes, 2000) for a fuller critique of the presence, nature and degree of psychopathology in the refugee population. In the present article (Hodes, 2002, this issue) he refers to his finding of increased rates of psychiatric disturbance in the refugee population, in contrast with comparison groups of immigrant children or indigenous population. I suggest that more research is necessary in order to replicate these results.

Lipsedge (2001), writing only last year in APT, pointed to the fallacy of the assumption of the validity of the psychiatric diagnostic framework when applied to the refugee population. As a clinician working with refugees in the UK and also overseas, where I work with children and young people who have been temporarily displaced and have remained in or near their country of origin, I am able to compare the groups. I am regularly struck by the difference in the nature and occurrence of their psychopathology, a difference seemingly dependent on their final destination. I recall comparing two groups of refugee children during the civil unrest in the former Yugoslavia: a group of Bosnian refugee children $(n=23)$ who had resettled together with their families in the UK, and a group of displaced, mainly Bosnian, refugee children who had arrived in neighbouring Croatia $(n=50)$ (further details available from the author upon request). The children in each group had experienced similar adversity. One of the central differences between the groups was a statistically significant lower level of educational achievement in the UK sample. Adjustment difficulties associated with resettlement problems, acculturation and language difficulties that must go along with resettlement appear to have a much greater influence than has hitherto been established in the research literature.

There are other factors that influence mental health outcomes in the refugee population, and 'dislocation and relocation' are one of the core experiences of refugees (Tata Arcel, 1995). For example, young people and children who have been looked after in families, when compared with those placed in hostels or communal refugee settlements, show decreased rates of psychopathology (Rudic et al, 1993). So mention of general, practical intervention, as suggested by Hodes, is most welcome. Befriending schemes, peer-group support, support from trusted members of the extended family and wider cultural community, housing and interpreting services, advocacy and competent legal services are more likely than a specific mental health intervention to assist both unaccompanied refugee youths and families with children and young people. Tiered approaches can follow, if needed. Hodes' description of a Tier 2 outreach service provided to a junior school was particularly interesting. Schools are the natural milieu for helping children and young people with minor disorders. The more severe cases will inevitably require the specialist services at Tier 3 and Tier 4 levels. The only question is the capacity of already stretched services to deal with rising numbers of refugees in urban settings. An integration across local agencies, including the voluntary sector, is imperative. How this will be affected by the Government's new proposals for preliminary segregation remains to be seen.

Hodes has written an article about service and treatment provision. It broadly reflects the care pathway for children and young people in the general population who access child and adolescent mental health services. Perhaps more emphasis could have been given to the need for overarching specialist services for the refugee population. The Refugee Council \& The Mental Health Foundation (1995) were among the first to pool information about mental health provision for refugees in Greater London, and together established a register of a wide range of services across agencies. To identify their remit, the compilers of the directory defined mental health 
problems along a continuum ranging from feelings of unhappiness and anxiety to extreme disruption of perception, thoughts and feelings. What was striking was both the specificity and at the same time diversity of services on offer by voluntary and statutory agencies with a focus on general practical interventions.

Hodes has written a stimulating paper on a subject to which he has devoted much clinical and research time. He has skilfully described the demographic and sociological aspects of the questions thrown up by refugee populations in general, and linked these with concepts of psychological trauma in children and adolescents and with treatment modalities. At the same time, he has managed to go a step further and succeed in formulating a set of multiple choice questions in an area where research information and clinical postulates are still all too scarce.

\section{References}

Derrida, J. (2001) On Cosmopolitanism. London: Routledge.

Hodes, M. (2000) Psychologically distressed refugee children in the United Kingdom. Child Psychology and Psychiatry Review, 5, 57-68.

- (2002) Implications for psychiatric services of chronic civilian strife: young refugees in the UK. Advances in Psychiatric Treatment, 8, 366-375.

Lipsedge, M. (2001) Commentary: Migration and mental illness. Advances in Psychiatric Treatment, 7, 222-223.

Refugee Council \& The Mental Health Foundation (1995) Directory of Mental Health Services for Refugees. London: Refugee Council \& The Mental Health Foundation.

Rudic, N., Rakic, V., Ispanovic-Radojkovic, V., et al (1993) In Stresses of War (eds P. Kalicanin, J. Bukelic, V. IspanovicRadojkovic, et al), pp. 85-89. Belgrade: Institute for Mental Health.

Tata Arcel, L. (1995) Multidisciplinary approach to refugee women and their families. In Psycho-Social Help to War Victims: Women Refugees and their Families from Bosnia and Hercegovina and Croatia (eds L. Tata Arcel, V. Folnegovic-Smalc, D. Kozaric-Kovacic, et al), pp. 23-32. Copenhagen: IRCT.

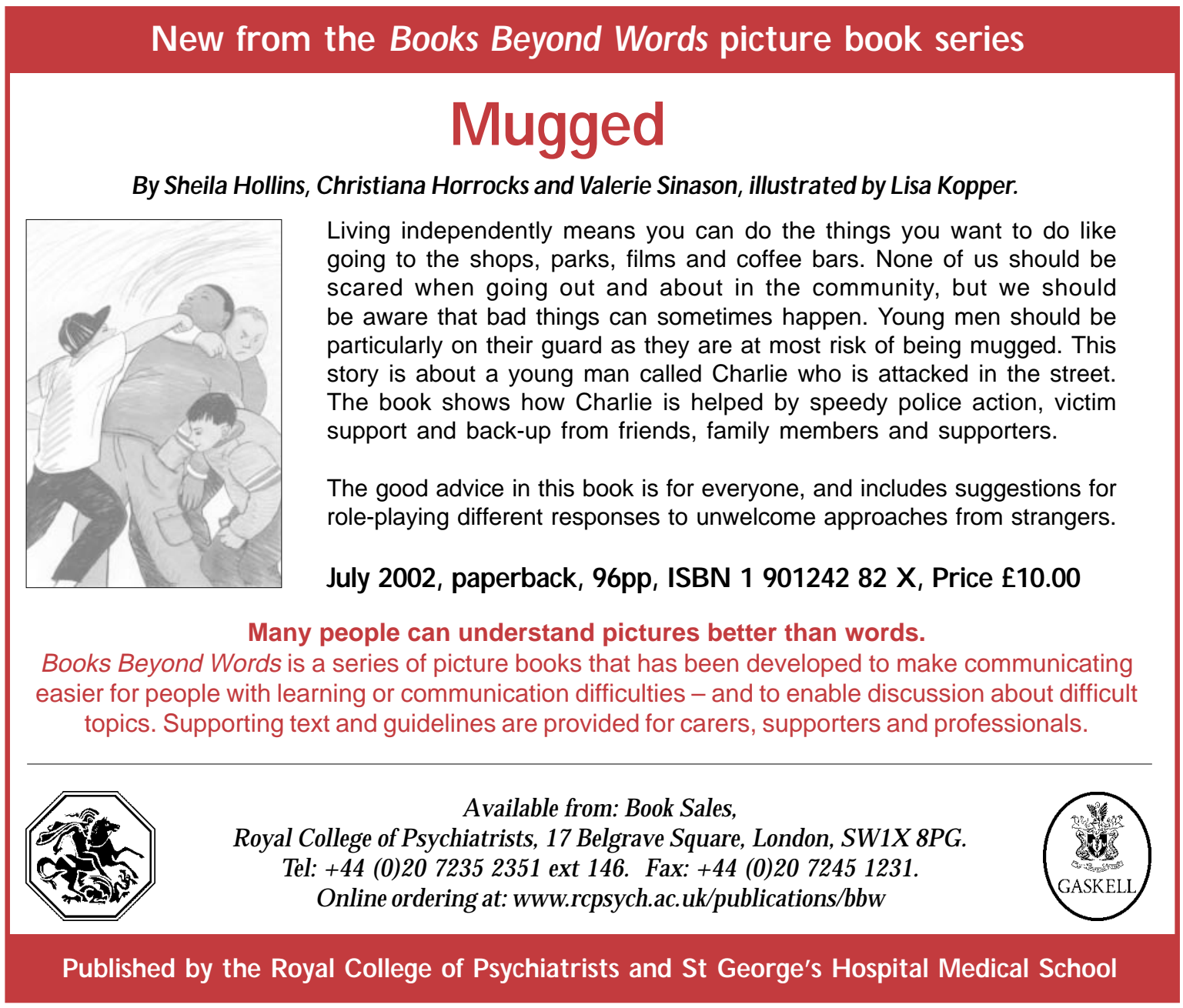

